\title{
Estudo de percepção da paisagem do rio Paranapanema no setor Ponte Pênsil (Chavantes, SP) ${ }^{1}$
}

\author{
Perception study of the Paranapanema river landscape in the Ponte Pênsil sector \\ (Chavantes, SP)
}

\author{
Helen Patrícia da Silva Costa ${ }^{A}$ \\ Luciene Cristina Risso ${ }^{B}$ \\ a Geógrafa formada pela Universidade Estadual Paulista "Júlio de Mesquita Filho" (Unesp), \\ campus de Ourinhos. \\ E-mail: helenpatricia739@gmail.com
}

${ }^{\text {b }}$ Professora doutora da Universidade Estadual Paulista (Unesp), campus de Ourinhos, doutora em Geografia pela Unesp, campus de Rio Claro.

E-mail: luciene.risso@unesp.br

\begin{abstract}
Este trabalho tem por objetivo levantar a percepção ambiental sobre a paisagem hídrica do rio Paranapanema na Ponte Pênsil Alves Lima, divisa entre os estados de São Paulo e Paraná. Para cumprir com os objetivos, a metodologia da pesquisa contou com revisão bibliográfica sobre o tema, levantamentos secundários, aplicação de questionários on-line, trabalho de campo, tabulação e interpretação dos dados. Foram entrevistadas 42 pessoas para o estudo de percepção ambiental. Esta pesquisa também visa servir de subsídio para planejamento ambiental e programas de educação ambiental, bem como apresentar essa paisagem como um patrimônio para a região, dada sua importância social, cultural e ecológica.

Palavras-chave: educação ambiental, Ourinhos, Chavantes, memórias.

This study investigates the environmental perception regarding the water landscape of the Paranapanema River, at Ponte Pênsil Alves Lima (border between the States of São Paulo and Paraná). Data collection included a literature review on the topic, secondary surveys, application of online questionnaires and field work. All data were tabulated and interpreted. The researchers interviewed 42 people to assess environmental perception. Its secondary goal is to serve as a subsidy for environmental planning and education programs, and to present this landscape as a heritage site for the region, given its social, cultural, and ecological importance.
\end{abstract}

Keywords: environmental education, Ourinhos, Chavantes, memoirs.

1 Este artigo é parte do trabalho de conclusão de curso de Helen Costa (2019). 


\section{INTRODUÇÃO}

O conceito de paisagem é fundamental para a compreensão da relação entre homem e natureza e apresenta uma longa trajetória na Geografia. Ainda assim, não há um acordo dentro dessa ciência sobre o conceito de paisagem, pois existem diversas abordagens que se diferenciam ao longo do tempo, de acordo com a corrente e a visão de cada autor.

Paisagem é comumente entendida como a materialização das relações do homem com a natureza, sendo representada na visão de alguns como tudo aquilo que a visão alcança e, na de outros, como algo além do visível.

Na década de 1970, o conceito de paisagem é retomado com a Geografia Humanista e, na década de 1980, pela nova Geografia Cultural. Logo, a Geografia Humanista nasce criticando a Geografia tradicional e passa a valorizar os sentimentos e as percepções dos indivíduos. Em síntese, a Geografia Humanista e Cultural considera as subjetividades da paisagem, ou seja, as experiências por meio de estudos de percepção ambiental, essenciais para entender o papel de determinada paisagem como produtora ou estimuladora de sentimentos (topofílicos ou topofóbicos), experiências e memórias.

Conforme Risso (2005, p. 104), "para cada pessoa ou grupo a paisagem terá um significado, porque, as pessoas atribuem valores e significados diferentes às suas paisagens". Além disso, a paisagem pode ser considerada como "[...] lócus de vivências e experiências, e como um lugar de grande potencial de inspiração para novos pensamentos, atitudes e geopoéticas" (RISSO, 2005, p. 314).

Por percepção ambiental, Del Rio (1996, p. 3), baseado em Tuan (2012), afirma que é "um processo mental de interação do indivíduo com o meio ambiente que se dá através de mecanismos perceptivos propriamente ditos [órgãos sensoriais] e, principalmente, cognitivos".

Um outro conceito com o qual compactuamos é o da Organização das Nações Unidas para a Educação, a Ciência e a Cultura (Unesco) (WHYTE, 1978, p. 3, tradução nossa), que afirma que a percepção ambiental "refere-se ao conjunto de processos (sensitivos, cognitivos e atitudinais) através dos quais o homem conhece individual e coletivamente seu ambiente e está predisposto a agir sobre ele"2.

A paisagem que pesquisamos é uma paisagem hídrica com muitas histórias e memórias, muito utilizada pelos habitantes da cidade de Chavantes (SP) e muito visitada pelas pessoas de Ourinhos (SP). Dessa forma, este estudo objetivou levantar a percepção ambiental e memórias em relação à paisagem do rio Paranapanema, na Ponte Pênsil Alves Lima - divisa entre os estados de São Paulo e Paraná. Os objetivos específicos foram: contribuir para a caracterização ambiental, a valorização cultural de paisagens e a produção de um folder, enquanto material educativo histórico. Esperamos também contribuir com o estudo de percepção ambiental na Geografia e com a valorização da paisagem de rios e de memórias.

\section{Metodologia}

A metodologia utilizada englobou pesquisas e revisão bibliográfica sobre o tema, além de levantamentos secundários, caracterização da paisagem e qualificação desta, buscando a percepção ambiental envolvida e outros valores imateriais. Numa segunda etapa, foi elaborado e aplicado um questionário para coleta de dados qualitativos na plataforma Google. Posteriormente, foram feitas entrevistas on-line, com o intuito de levantar memórias referentes às paisagens e à percepção ambiental dos indivíduos.

A pesquisa geográfica contou com trabalhos de campo, que foram essenciais para estratégias de observação, coleta e verificação de dados. Os equipamentos utilizados foram diários de campo e câmera fotográfica. A terceira etapa compreendeu a interpretação do banco de dados, tanto objetivos (materiais) como subjetivos (imateriais), dessa paisagem.

Após a interpretação dos resultados, constatou-se que a maioria dos entrevistados desconhecia a história sobre a Ponte Pênsil Alves Lima. Nesse sentido, surgiu a ideia de confeccionar um folder informativo-educativo feito no software Microsoft PowerPoint, com o intuito de sensibilizar a população acerca da importância da preservação dessa paisagem.

2 Original: "hace referencia al conjunto de procesos (sensitivos, cognitivos y actitudinales) a través de los cuales el hombre individual y colectivamente conoce su entorno y se predispone a actuar sobre él". 


\section{A história da Paisagem da Ponte Pênsil Alves Lima (Chavantes, SP)}

Localizada no município de Ribeirão Claro (PR), sobre o leito do rio Paranapanema, na divisa dos municípios de Ribeirão Claro e Chavantes (SP), a Ponte Pênsil Alves Lima é pertencente aos dois referidos estados brasileiros.

De acordo com dados do Instituto Brasileiro de Geografia e Estatística (IBGE, [201-?]), a cidade de Chavantes possui uma população de aproximadamente 12.418 habitantes, enquanto a cidade de Ribeirão Claro possui cerca de 10.693 habitantes. Sendo uma das três pontes pênseis já construídas no Brasil, ela permite a ligação entre as duas cidades. As outras duas construções dizem respeito à Hercílio Luiz (SC) e, a mais antiga, São Vicente (SP), construída em 1914 (RIBEIRÃO..., [201-?]).

Antes de ser intitulada "Ponte Pênsil de Chavantes", era chamada pela população de "Ponte do Emygdião ou Hermidão", e recebeu o nome oficial de Ponte
Alves Lima em homenagem a seu último construtor. Foi Manoel Antônio Alves Lima, possessor da fazenda Monte Claro, localizada nas proximidades e na margemesquerda do Paranapanema, quem tomou a frente do projeto e solicitou a construção da ponte com auxílio financeiro do município de Ribeirão Claro e Chavantes (RIBEIRÃO..., [201-?]).

A Ponte Pênsil Alves Lima foi inaugurada no dia 4 de dezembro de 1920, objetivando conectar a cidade com a estação Chavantes da Estrada de Ferro Sorocabana. A ponte representou

a "salvação da lavoura" na época em que foi construída. Para confirmar a sua importância, a prefeitura de Ribeirão Claro deu, em 1926, a assistência de três contos de réis para a construção da estrada, no Estado de São Paulo, ligando a ponte até Chavantes. (RIBEIRÃO..., [201-?], p. 1)

O mapa da figura 1 representa o local onde a ponte está situada.

Figura 1. Mapa de localização da área de pesquisa. MAPA DE LOCALIZAÇÃO DA PONTE PENSIL ALVES LIMA SP-PR (2018)

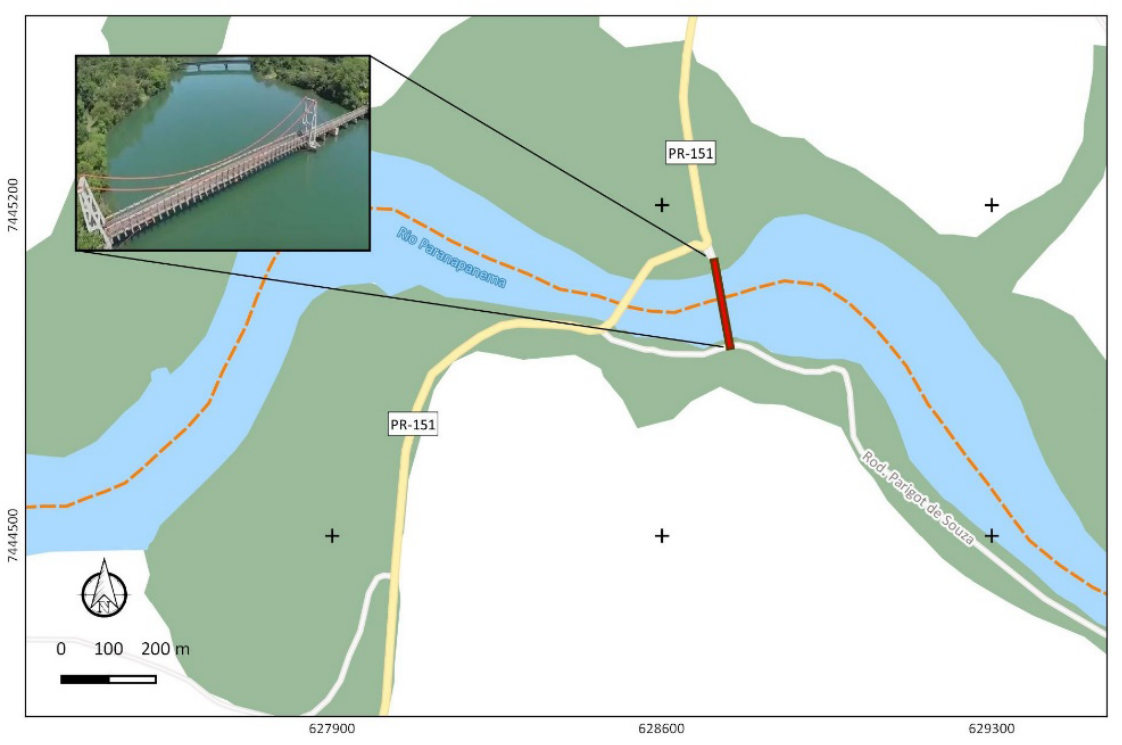

Fonte: Costa (2019)

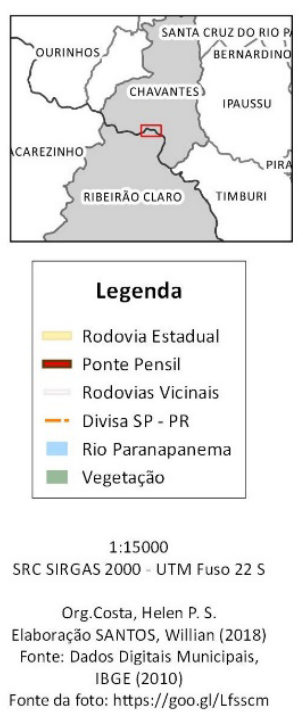

Documentadamente, o Norte Pioneiro paranaense foi colonizado por meio de uma ocupação de grupos paulistas e mineiros, trazendo a cultura do café para o Paraná. A transposição de rios como o Paranapanema

3 Segundo conta Maria Helena Cadamuro, do Museu Histórico de Chavantes, ao se referir a uma contribuição de Emygdio Piedade. significou uma dificuldade a mais, principalmente na hora de transcorrer a produção. Meios de transporte precários e a ausência de estradas eram a angústia daqueles que se assentaram nas novas terras que, se por um lado eram generosas, por outro dificultavam o deslocamento de suas riquezas para os centros consumidores (RIBEIRÃO..., [201-?]). 
De início, a passagem do rio Paranapanema entre os estados era feita por balsa, consistindo em um processo que não oferecia condições de segurança. Logo, com a ascensão da produção cafeeira, os fazendeiros da região se mobilizaram para superar as dificuldades, construindo uma estrada de ferro, que foi sucedida pela ponte pênsil. Contudo, a ponte nem sempre esteve em um ambiente de estabilidade. Na verdade, já passou, no mínimo, por três adversidades (ALONSO, 2018; RIBEIRÃO..., [201-?]).

A primeira ocorreu em 1924, durante a segunda revolução tenentista, quando as tropas do capitão Alberto Costa invadiram a cidade de Chavantes e a ponte foi completamente queimada, sendo reconstruída em 1928. Por sua vez, o segundo infortúnio ficou marcado pela Revolução Constitucionalista de 1932, período no qual a Ponte Alves Lima foi dinamitada. Tropas gaúchas ficaram alojadas em Ribeirão Claro, exigindo alimentos e outros suprimentos da população. Forçados pelos gaúchos, os revolucionários paulistas retrosseguiram e dinamitaram a ponte para impedir a passagem dos sulistas (RIBEIRÃO..., [201-?]).

Sua reconstrução pelo governo de São Paulo só teve fim em 1935, apesar de ter sido iniciada em 1934 (figura 2).

Figura 2. Reconstrução da ponte.

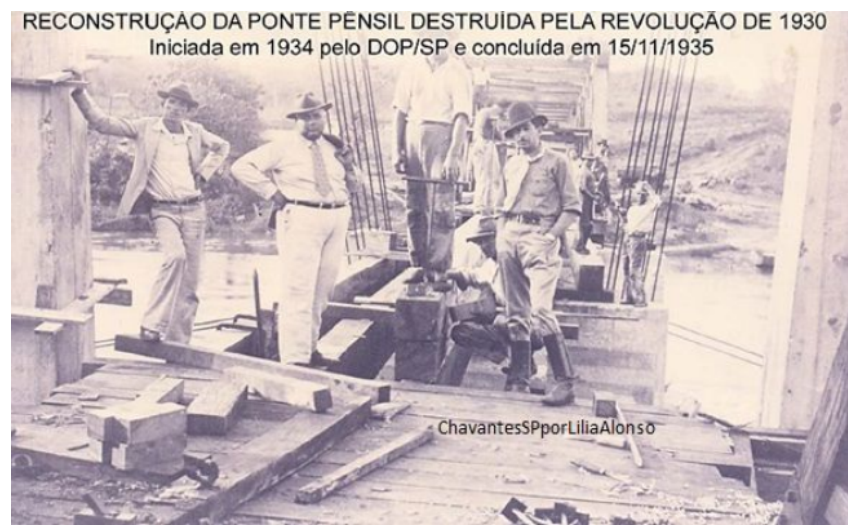

Fonte: Alonso (2018).

Na última das adversidades, ocorrida em 1983, a atuação da força da natureza fez com que a ponte fosse destruída após a maior enchente já presenciada na região (figura 3).
Figura 3. Enchente na Ponte Pênsil Alves Lima (1983).

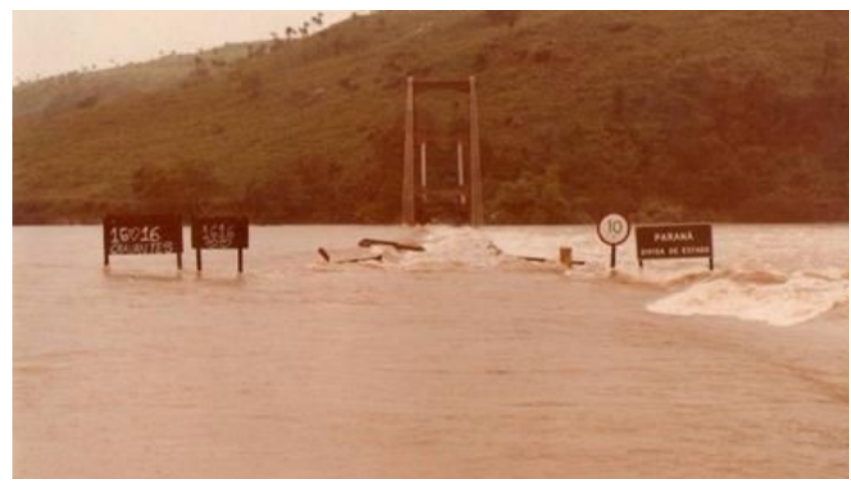

Fonte: Alonso (2018).

Em 1985, a ponte foi restaurada e tombada pelo Conselho de Defesa do Patrimônio Histórico, Arqueológico, Artístico e Turístico do Estado de São Paulo (Condephaat), através da resolução n ${ }^{\circ} 65$, de 2 de março de 1985 (CONDEPHAAT, 2007) e, em 2011, pelo governo do Paraná (SEEC, [201-?]).

Contudo, sem medidas de manutenção e sendo alvo de depredação, a ponte pênsil apresentou riscos à população que transitava por ela, permanecendo esquecida por alguns anos. Devido ao seu estado estrutural debilitado (figura 4), a ponte pênsil foi interditada em 2006 (ALONSO, 2018).

Figura 4. Cenário da ponte pênsil antes do restauro pela FormArte.

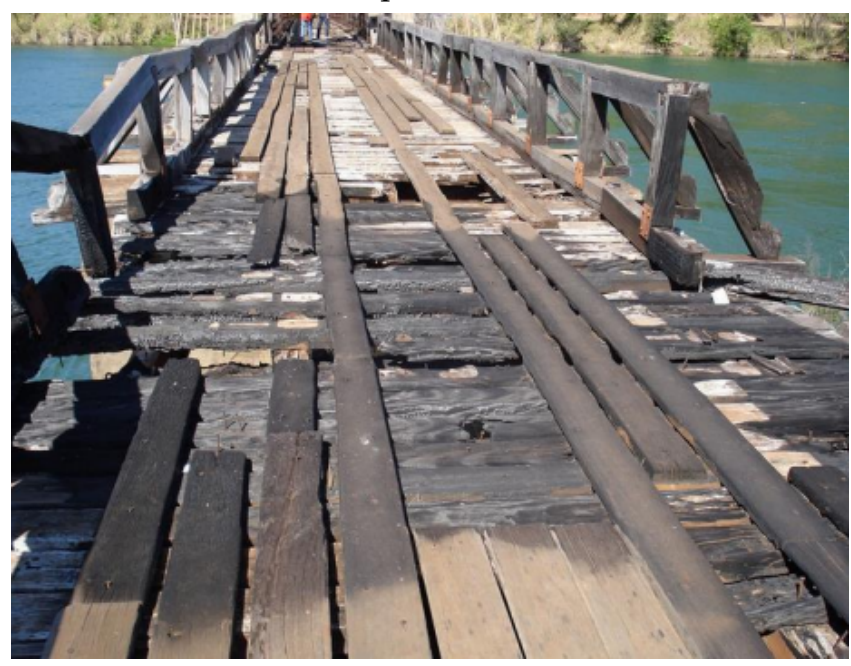

Fonte: FormArte (2019). 
Para não impedir o trânsito de veículos entre os dois estados, construiu-se, em 2006, uma outra ponte ao lado, desta vez de concreto, para transporte de veículos (figura 5).

Figura 5. Ponte de concreto construída em 2006.

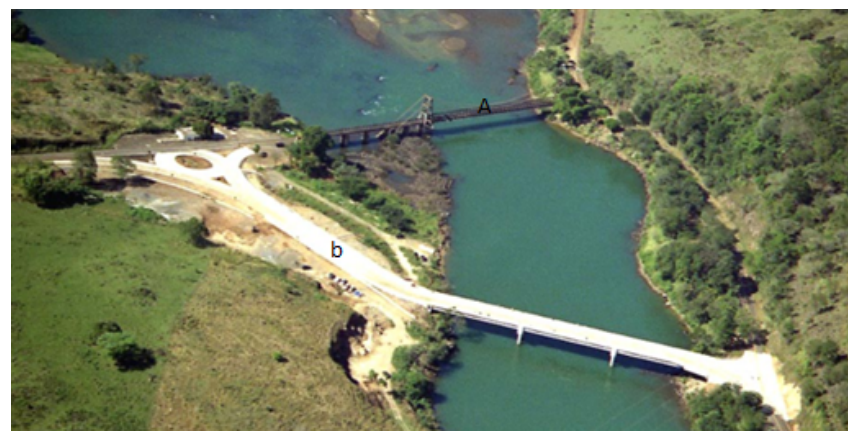

Fonte: Foto da prefeitura de Chavantes. A) Ponte pênsil histórica; B) Ponte de concreto.

Em 2009 a Ponte Pênsil Alves Lima foi novamente restaurada (figura 6), mas, dessa vez, a reconstrução foi subsidiada por um grupo de responsáveis pelas hidrelétricas localizadas na extensão do rio Paranapanema, como forma de compensação pelo seu uso. Iniciou-se o processo de restauração da ponte, concluído em 2011, quando a ponte foi novamente reinaugurada (ALONSO, 2018).

Atualmente, a ponte histórica é uma atração turística. $\mathrm{O}$ acesso a ela se dá por ambos os lados (São Paulo e Paraná), mas restrito aos pedestres. A ponte tem 149 metros de extensão e possui um vão suspenso de 82 metros.

Figura 6. Ponte Pênsil Alves Lima.

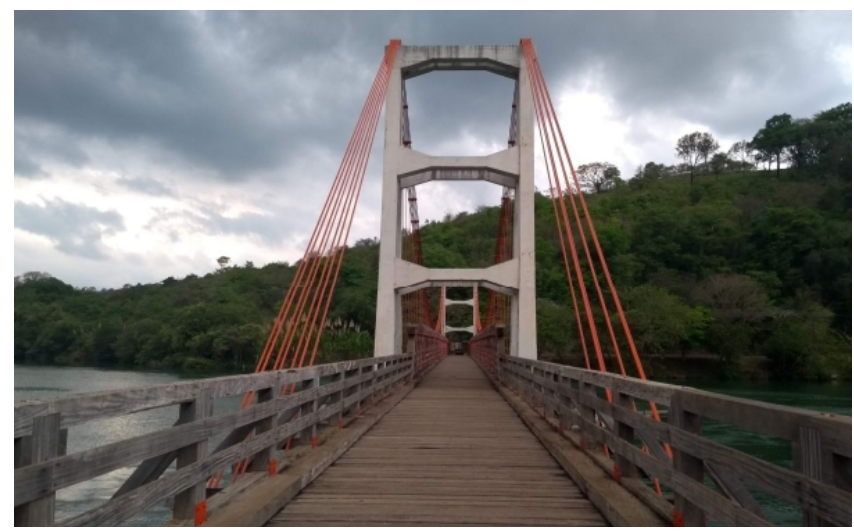

Fonte: Foto de Helen Costa (2018).

Infelizmente, em 7 de novembro de 2020, próximo ao aniversário de 100 anos da ponte (que se daria em 4 de dezembro), aconteceu um incêndio criminoso, iniciado no lado paranaense, destruindo parte da estrutura de madeira que liga os estados (figuras 7, 8 e 9). Os governos de ambos os estados se propuseram a restaurar novamente a parte danificada, porém, até julho de 2021 nada havia sido feito.

Figura 7. Bombeiro controlando o fogo na ponte pênsil em 2020.

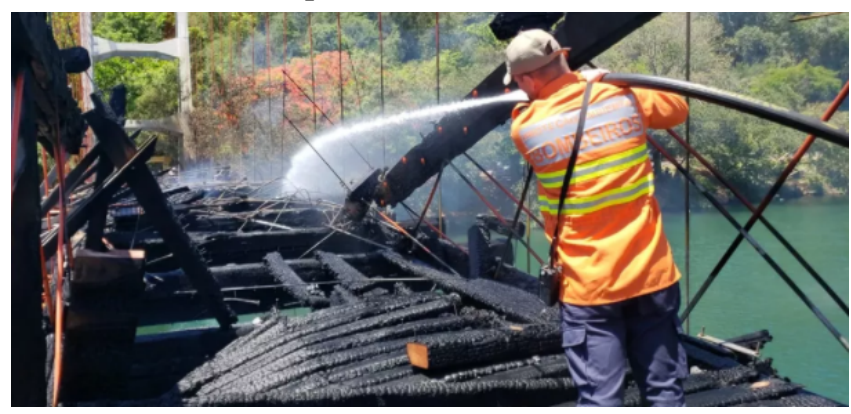

Fonte: G1 (INCÊNDIO..., 2020).

Figura 8. Parte da ponte pênsil queimada, vista da ponte de concreto, 10 de julho de 2021.

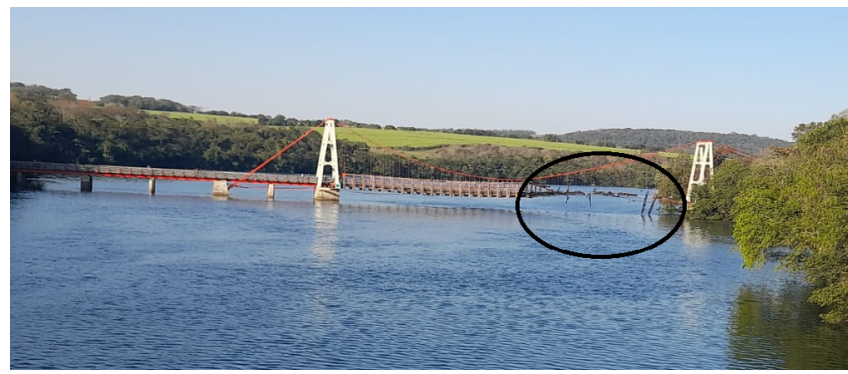

Fonte: Foto de Luciene C. Risso (2021).

Figura 9. Parte detalhada da ponte pênsil queimada. Perspectiva a partir do Paraná, julho de 2021.

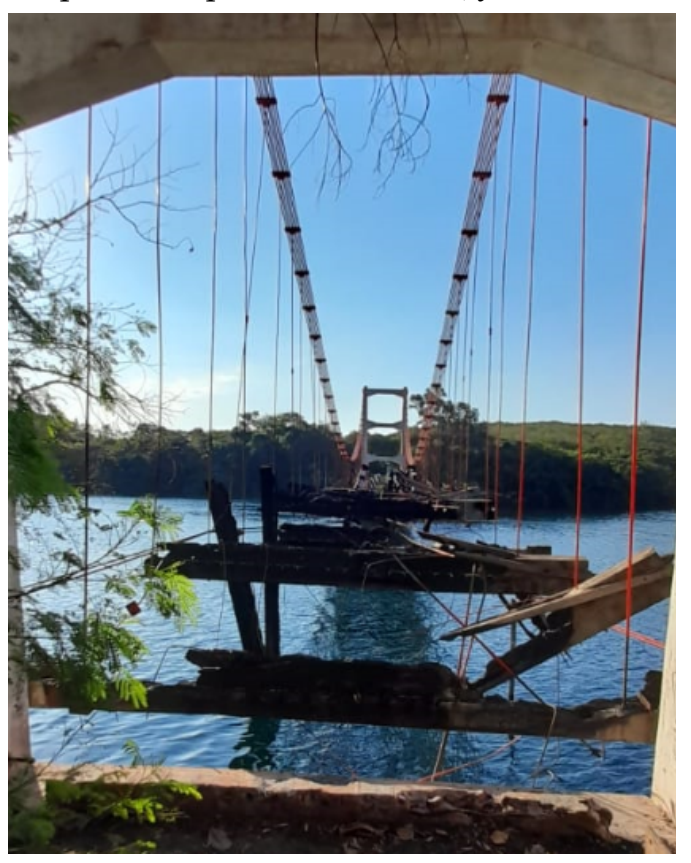

Fonte: Foto de Luciene C. Risso (2021). 
Como está escrito na placa da figura 10, a ponte histórica já passou por vários contratempos, mas sempre foi e será reconstruída. Assim, esperamos que a parte danificada da ponte seja restaurada logo, uma vez que as pessoas valorizam esse lugar. Inclusive, na última visita só ouvimos lamentações dos visitantes sobre o estado da ponte.

Figura 10 - Placa próxima à ponte pênsil do lado de São Paulo.

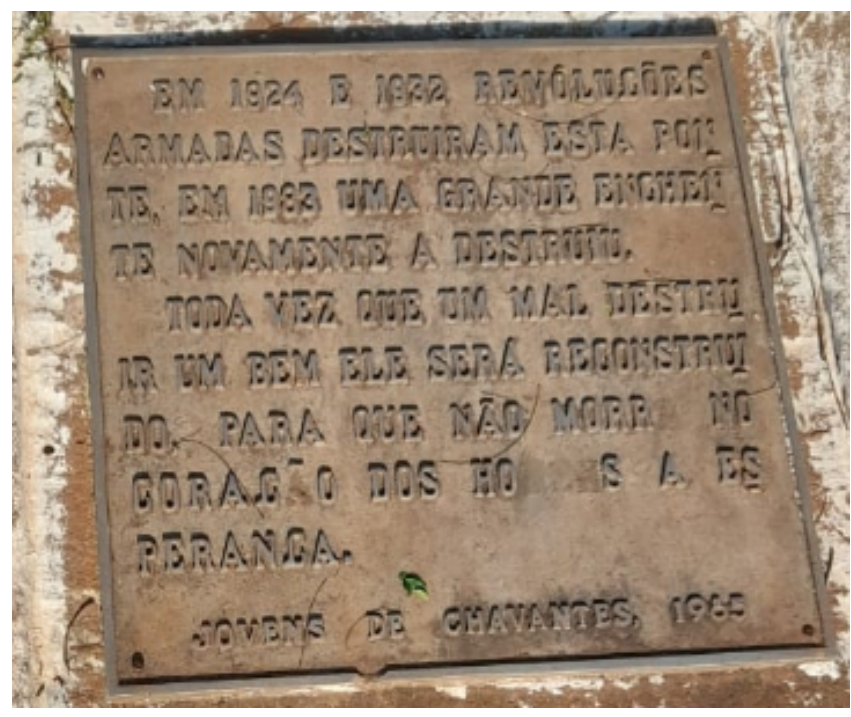

Fonte: Foto de Luciene C. Risso (2021).

\section{Resultados}

Uma parte dos resultados apresentados neste artigo podem ser visualizados integralmente no trabalho de conclusão de curso de Costa (2019). A percepção ambiental foi obtida mediante a aplicação de 42 entrevistas e os questionários foram divulgados por meio das redes sociais e publicados em grupos de diversas cidades da região, como Ourinhos, Chavantes e Ribeirão Claro.

Com relação às entrevistas aplicadas por meio do questionário on-line, dos 42 entrevistados, 23 se identificaram como sendo do gênero feminino e 19 do gênero masculino. A maioria se enquadra na faixa etária de 18 a 25 anos.

Dos 42 inquiridos, $70 \%$ residem na cidade de Ourinhos, São Paulo. No que diz respeito à escolaridade, 23 possuem ensino superior completo, 11 ensino superior incompleto, 5 ensino médio completo e apenas 1 possui ensino médio incompleto.
Todos os entrevistados já visitaram a ponte pênsil, mas a maioria (33 pessoas) relatou não conhecer nada a seu respeito, como podemos observar no gráfico da figura 11.

Figura 11 - Conhecimento sobre a ponte pênsil.

Você sabe alguma coisa sobre a Ponte Pênsil do rio Parapanema?

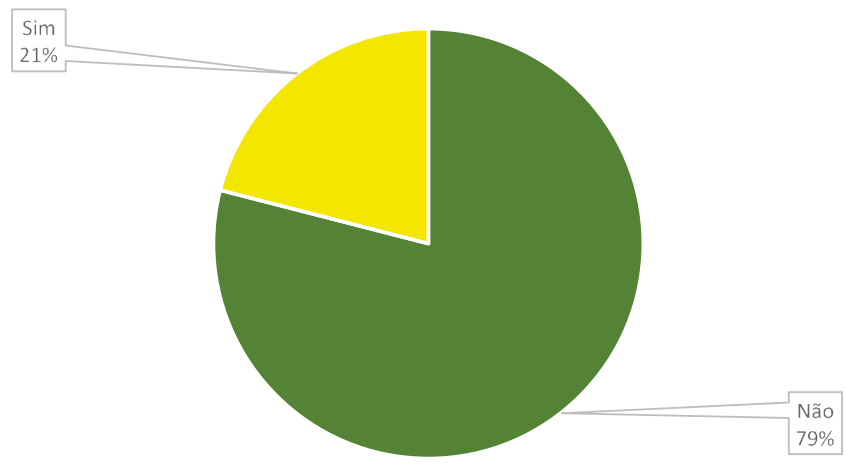

Outra questão presente no questionário tratava da opinião acerca da conservação ambiental das matas do rio Paranapanema. Como mostra a figura 12, 50\% dos entrevistados disseram que a conservação ocorre em nível médio.

Figura 12 - Opinião sobre a conservação das matas e do rio Paranapanema.

Qual sua opinião sobre a conservação ambiental das matas e do rio Paranapanema?

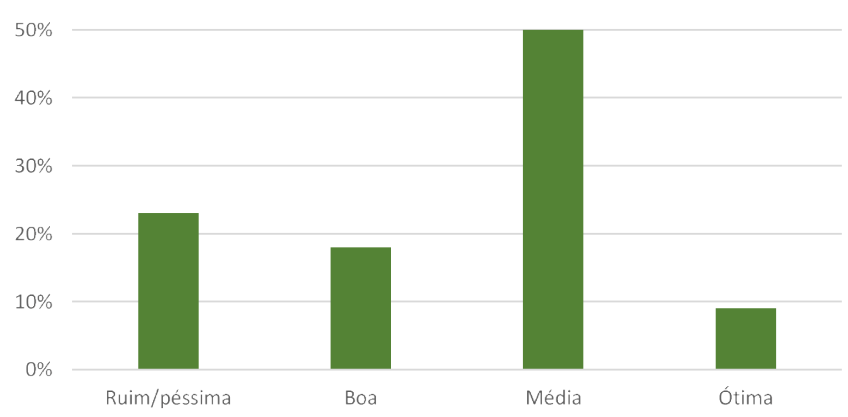

Com base nas respostas da pergunta anterior, os entrevistados foram questionados a respeito da conservação ambiental do rio Paranapanema e das matas em seu entorno. A maioria das respostas evidenciou o ponto no qual essa paisagem hídrica deve ser mais conservada: "O rio tem pouca mata ciliar" (Entrevista 7). Dentre outras:

Primeiramente que há gigantescas plantações de cana de açúcar que são pulverizadas por venenos e pesticidas que são levados pelas chuvas para o Rio. Segundo, as matas 
ciliares, em alguns pontos, não existem, e fica visível que o assoreamento das margens está cada vez mais intenso, uma vez que conta com grande quantidade de argila e areias que são utilizadas na construção civil. (Entrevista 3)

Alguns trechos melhores que outros, mas a conservação é prejudicada pelas próprias represas, hidroelétricas ao longo do rio, lixo humano mesmo, pois na ponte pênsil não há uma fiscalização e tem crescido o número de visitantes lá. (Entrevista 6)

Alguns dos problemas relatados pelos entrevistados foram observados no trabalho de campo realizado no local. Na experiência empírica, notou-se certo descaso com essa área, que deveria estar preservada. Notou-se também a presença de lixo nas margens do rio, bem como a inexistência de cobertura vegetal, solo exposto, ausência de contentores de coleta seletiva, guardas ambientais etc.

Os entrevistados também foram questionados sobre o porquê de visitarem o Paranapanema: 89\% responderam que vão ao rio para o próprio lazer, $7 \%$ disseram que frequentam o Paranapanema para trabalho (comercializar produtos) e $4 \%$ o visitam para outros fins, dentre eles a prática de rituais religiosos. Nesse sentido, destaca-se a questão religiosa, pois a água é vista como símbolo sagrado em diversas culturas e crenças. Assim, "as religiões sempre tiveram uma relação simbólica com a água, isso é mostrado em textos sagrados ou em celebrações como o de batismo, representando o nascimento e a purificação" (PRADEICZUK; RENK; DANIELI, 2015, p. 22).

Considerando que a cultura se manifesta por meio de variadas formas, valores e crenças, foi perguntado aos entrevistados se conhecem mitos, tradições e/ou lendas vinculados à ponte e ao rio Paranapanema: 36 pessoas disseram desconhecer qualquer tipo de representação do imaginário popular. Logo, apenas 6 disseram conhecer algumas histórias de eventos paranormais na região da ponte pênsil. Alguns relatos mencionaram a presença de assombrações por conta das muitas mortes que aconteceram no local, mitos sobre peixes gigantes, barulhos estranhos, dentre outros.

Meu pai conta que o avô dele foi pescar uma vez e ouvia uma música vinda da mata, mas não tinha nada lá, reza a lenda que era música que os soldados escutavam quando estavam lá, antes de morrerem. (Entrevista 16)
Quando indagados sobre "o que o Rio Paranapanema significa para você?", a maioria das pessoas relatou que o rio representa beleza, vida, tranquilidade, prosperidade e paz. Assim, como a pesquisa tem caráter qualitativo, foram selecionadas algumas percepções:

Fui criado dentro do rio. Representa para mim a única coisa da natureza que se manteve preservada. Muito usado pra o lazer e alimentação. Representa vida. (Entrevista 35)

É um lugar de calma, com a paisagem que me traz tranquilidade e de muita beleza natural, apesar de mal conservado. (Entrevista 4)

Perda. Perdi um primo naquele rio um dia depois do Natal. (Entrevista 8)

O rio Paranapanema para mim, representa, primeiramente, vida, embora seja represado em várias alturas de seu curso, ainda conta uma enorme quantidade de peixes que alimenta várias pessoas que moram em bairros periféricos próximos a sua margem (em relação a parte que banha o município de Ourinhos). O rio também me serve para entrar em contato com meu eu, me permite trabalhar minha espiritualidade. (Entrevista 3)

Nesse sentido, os entrevistados sugeriram algumas medidas e melhorias para o local para que a população o visite mais. Dentre as sugestões, $29 \%$ dos inquiridos sugeriram medidas de conscientização e educação ambiental, 24\% disseram que se deve melhorar a infraestrutura do local, $17 \%$ relataram que deve haver mais segurança, 14\% sugeriram investimentos no turismo, 9\% destacaram que é necessário transporte até o local e cerca de 7\% relataram que é preciso um manejo adequado na área. Algumas das sugestões são notórias nas seguintes falas:

Acho que a segurança, no verão a quantidade de mortes no rio é muito alta. (Entrevista 2)

Criação de estrutura física, programas de educação ambiental e criação de mais áreas de proteção. (Entrevista 34)

Por fim, produziu-se um folder como material educativo da área de pesquisa, visando a educação ambiental e patrimonial dessa paisagem. 


\section{Proposta do Folder INFORMATIVO-EDUCATIVO}

Machado (c2006), em seu artigo para a revista Planeta Educação, baseado no Dicionário Houaiss da língua portuguesa, afirma que o folder é:

um impresso de pequeno porte, constituído de uma só folha de papel, com uma ou mais dobras e que apresenta conteúdo informativo ou publicitário; "folheto" ou ainda "prospecto dobrável". Num exame etimológico da palavra folder, de origem inglesa, aparecem referências como "folheto dobrado", "o que dobra" ou ainda a derivação deste vocábulo do verbo to fold, ou seja, dobrar. (MACHADO, c2006, p. 1)

Assim, o folder informativo-educativo (figuras 13 e 14) apresenta um caráter dinâmico e tem como função passar informações de formas objetiva e didática, procurando fomentar a curiosidade do leitor e servindo de subsídio para a educação ambiental. Sendo assim, considera-se que a educação ambiental deve:

[...] promover a compreensão dos problemas socioambientais em suas múltiplas dimensões: geográficas, históricas, biológicas, sociais e subjetivas, considerando o ambiente como o conjunto das interrelações que se estabelecem entre o mundo natural e o mundo social, mediado por saberes locais e tradicionais, além dos saberes científicos. (CARVALHO, 2004, p. 21)

Em vista disso, devido tanto à falta de informação apresentada pelos entrevistados a respeito da história da ponte pênsil quanto às sugestões sobre projetos de conscientização ambiental, surgiu a ideia de elaborar um folder informativo-educativo, contribuindo assim para a popularização da ciência.

Logo, faz-se necessário divulgar o saber científico por meio de recursos alternativos, uma vez que se deve divulgar o que se aprende no universo acadêmico. Sendo assim, escrever para todos, quando estudamos a natureza, os seres humanos ou a sociedade, exige vontade de representar o que imaginamos, entendemos ou acreditamos entender com palavras e desenhos. Acostumados a escrever para o leitor especializado, não o fazemos com a mesma naturalidade para o público comum e leigo (CANDOTTI, 2002, p. 15).

Para a elaboração do folder, primeiramente se pensou na divisão da estrutura do papel em três colunas, para que, depois de impresso, ele pudesse ser dobrado de maneira sequencial.

Posteriormente, iniciou-se o processo de confecção virtual do material no software Microsoft PowerPoint. Foi preciso coletar as principais informações acerca do patrimônio, tais como sua história e a problemática da vegetação de seu entorno, que deveria estar preservada.

Desse modo, ao final da elaboração, tal material constituiu um valioso instrumento que, depois de concretizado, poderá auxiliar na introdução de práticas iniciais de cuidado e zelo dessa paisagem hídrica. A ideia central é que esse material ultrapasse limites e que, futuramente, seja divulgado com máximo alcance, juntamente com outros meios de conhecimento e conscientização, de modo que a população - visitante ou não -, valorize e pratique as orientações, por enquanto teóricas, que o material apresenta. 
Costa H. P. S. \& Risso L. C.

Figura 13 - Parte externa do folder.

Então, vamos proteger este rio e sua mata ciliar?

Mas o que são matos ciliares?

São as vegetoções que se desenvolvem às margens dos rios, córregos e outros corpos d’água.

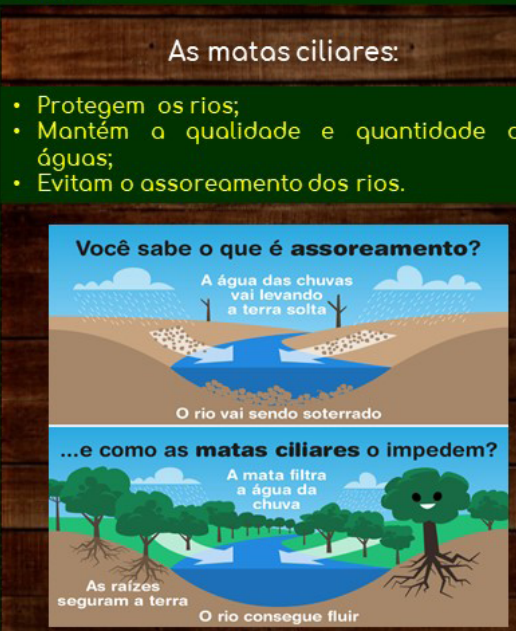

Fonte:Árvore, Ser Tecnológico.

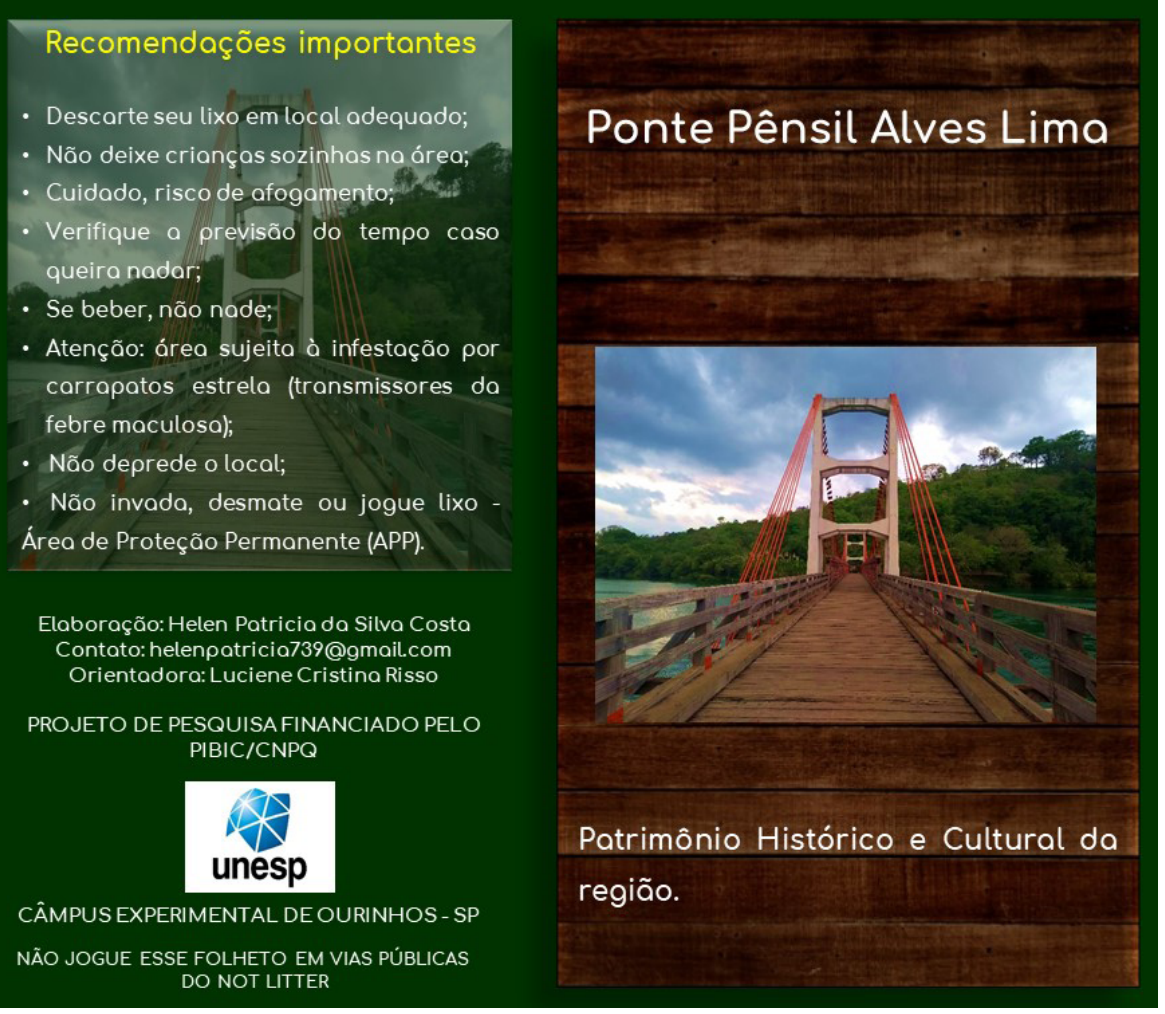

Fonte: Costa (2019, p. 43-44).

Figura 14 - Parte interna do Folder.

\section{Ponte Pênsil Alves Lima}

É uma das principais pontes pênseis já construídas no Brasil, e permite a ligação entre as cidades de Ribeirão Claro (PR) e Chavantes (SP).

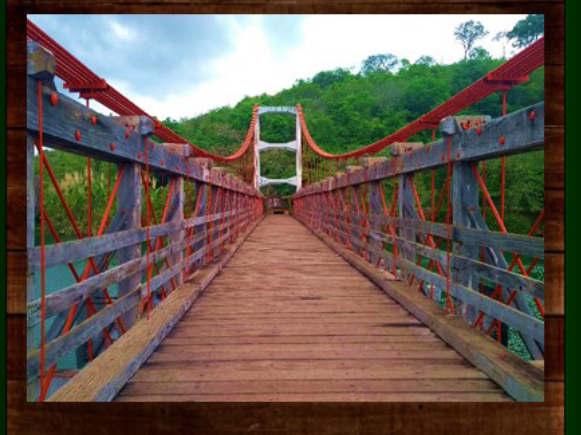

Já se passaram mais de 100 anos desde sua construção, mas poucos conhecem sua história.

DESTRUÍDA TRÊS VEZES...

1924- Destruída durante a Revolução Paulista;

\section{Reconstrução:1928}

1932- Destruída com dinamites durante o Revolução Constitucionalista;

Reconstrução: 1936

1983- Destruída devido à histórica cheia do Rio Paranapanema;

Reconstrução: 1985

Contudo, sem medidas de manutenção e sendo alvo de depredação, a ponte pênsil apresentou riscos à população que transitava por ela, permanecendo esquecida por alguns anos, até ser reconstruida entre os anos de 2009 a 2011.

\section{VOCÊ SABIA?}

Devido à sua importância histórica e cultural, a ponte foi tombada no ano de 1985 pelo Conselho de Defesa do Patrimônio Histórico, Arqueológico, Artístico e Turístico do Estado de São Paulo através do CONDEPHAAT e em 2001 pelo Conselho Estadual do Patrimônio Histórico do Paraná.

Está localizada sobre o rio Parananema que é considerado o mais limpo do estado de São Paulo, fazendo dessa paisagem um importante ponto turístico da região.

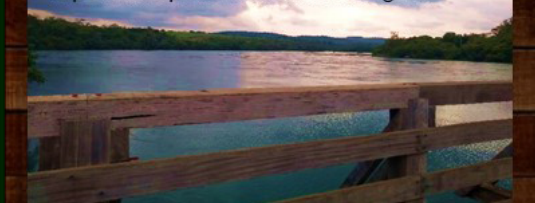

Fonte: Costa (2019, p. 43/44). 


\section{Considerações Finais}

Este trabalho revelou que a maior parte dos entrevistados $(79 \%)$ desconhece a história da Ponte Pênsil Alves Lima. Contudo, a maioria se mostrou sensível a respeito da questão da preservação ambiental. Através de suas percepções, destacaram problemas, preocupações e sugestões acerca dessa paisagem. Sendo assim, medidas como projetos de conscientização e educação ambiental podem ser importantes ferramentas para que a população preserve e conheça mais a região em que vive, além de contribuir para o registro de memórias dos municípios de Chavantes e Ribeirão Claro.

Baseando-se na interpretação das entrevistas, vale destacar a importância da percepção ambiental nas políticas de planejamento e gestão pública, pois a participação popular é de suma importância para que ocorra uma gestão mais efetiva das tomadas de decisão socioambientais.

Este estudo, utilizando a metodologia da Geografia Humanista Cultural, possibilitou a interpretação da paisagem hídrica do rio Paranapanema por meio de várias perspectivas espaciais e temporais, além de diferentes interferências humanas que perpassam modos de produção e que constroem histórias do imaginário popular.

Assim, de acordo com os resultados obtidos, pode-se concluir que faltam medidas de educação ambiental que zelem pelo patrimônio regional. Além disso, é necessária maior variedade de trabalhos acadêmicos que perpassem os muros da universidade e alcancem a população, para que esta se sensibilize acerca das questões socioambientais.

$\mathrm{O}$ folder informativo-educativo foi um instrumento importantíssimo para a educação ambiental não formal. Sendo assim, espera-se que este material alcance a população regional de maneira integrada, fazendo com que os habitantes se mobilizem e cobrem medidas dos órgãos públicos, reivindicando a preservação do patrimônio local, além de buscarem iniciativas próprias, com o objetivo de manter e cuidar da paisagem hídrica.

\section{REFERÊNCIAS}

ALONSO, L. Chavantes/SP. In: ALONSO, L. Blog de Lilia Alonso, [s. l.], 2018. Disponível em: https://bit. ly/3rFMTqd. Acesso em: 20 ago. 2018.

CANDOTTI, E. Ciência na educação popular. In: MASSARANI, L.; MOREIRA, I. C.; BRITO, F. (org.).
Ciência e público: caminhos da divulgação científica no Brasil. Rio de Janeiro: Editora UFRJ, 2002. p. 15-23

CARVALHO, I. G. M. Educação ambiental crítica: nomes e endereçamentos da educação ambiental. In: LAYRARGUES, P. P. (org.). Identidades da educação ambiental brasileira. Brasília, DF: MMA, 2004. p. 13-24.

CONDEPHAAT. Ponte pênsil de Chavantes. Condephaat, São Paulo, 1 mar. 2007. Disponível em: https://bityli.com/6NXOc. Acesso em: 15 jul. 2018.

COSTA, H. P. S. Percepção ambiental do rio Paranapanema no setor da ponte pênsil Alves Lima (divisa entre os estados de São Paulo e Paraná). 2019. Trabalho de Conclusão de Curso (Bacharelado em Geografia) - Universidade Estadual Paulista "Júlio de Mesquita Filho", Ourinhos, 2019.

DEL RIO, V.; OLIVEIRA, L. (org.). Percepção ambiental: a experiência brasileira. São Paulo: Studio Nobel; São Carlos: EdUFSCar, 1996.

FORMARTE. Projetos finalizados: Ponte Pênsil Alves de Lima. [S. 1.]: Formarte, 2019. Disponível em: https://bit.ly/3xBy4Xd. Acesso em: 12 mar. 2019.

IBGE. Cidades. Rio de Janeiro: IBGE, [201-?]. Disponível em: https://bit.ly/2VhXhsf. Acesso em: 5 ago. 2018.

INCÊNDIO destrói ponte pênsil centenária sobre o Rio Paranapanema entre SP e PR. G1, G1 Bauru e Marília, Rio de Janeiro, 7 nov. 2020. Disponível em: https://bityli.com/piAVV. Acesso em: 29 jul. 2021.

MACHADO, J. L. A. Aprendendo com os folders. Planeta Educação, [s. l.], c2006. Disponível em: https://bityli.com/ApJrq. Acesso em: 20 mar. 2019.

PRADEICZUK, A.; RENK, A.; DANIELI, M. A. Percepção ambiental no entorno da unidade de conservação Parque Estadual das Araucárias. Grifos, Chapecó, v. 24, n. 38-39, p. 13-32, 2015.

RIBEIRÃO Claro: Ponte Pênsil Alves Lima. Ipatrimônio, [s. l.], [201-?]. Disponível em: https://bityli.com/A0wZm. Acesso em: 3 dez. 2018. 


\section{RISSO, L. Paisagem, cultura e desenvolvimen-}

to sustentável: um estudo da comunidade indígena Apurinã na Amazônia brasileira. 2005. Tese (Doutorado em Geografia) - Instituto de Geociências e Ciências Exatas, Universidade Estadual Paulista "Júlio de Mesquita Filho", Rio Claro, 2005.

RISSO, L. G. Vivências paisagísticas como caminhos para novas percepções e experiências. Geograficidade, Niterói, v. 10, p. 309-323, 2020. Disponível em: https://bit.ly/3fb90Qi. Acesso em: 29 jul. 2021.
SEEG. Ponte Pênsil Alves Lima. Patrimônio Cultural, Curitiba, [201-?]. Disponível em: https://bityli.com/ PyWZG. Acesso em: 20 jun. 2018.

TUAN, Y. Topofilia: um estudo da percepção, atitudes e valores do meio ambiente. Tradução: Lívia de Oliveira. Londrina: Eduel, 2012.

\section{WHYTE, L. La perception de l'environnement:} lignes directrices méthodologiques pour les études sur le terrain. Paris: UNESCO, 1978. Notes techniques du MAB 5. 